\title{
Maurice Scève, Délie, object de plus haulte vertu
}

\section{Dario Cecchetti}

\section{(2) OpenEdition}

\section{Journals}

\section{Edizione digitale}

URL: http://journals.openedition.org/studifrancesi/35877

DOI: 10.4000/studifrancesi.35877

ISSN: 2421-5856

\section{Editore}

Rosenberg \& Sellier

\section{Edizione cartacea}

Data di pubblicazione: 1 juillet 2005

Paginazione: 146

ISSN: 0039-2944

\section{Notizia bibliografica digitale}

Dario Cecchetti, «Maurice Scève, Délie, object de plus haulte vertu», Studi Francesi [Online], 145 (XLIX |I) | 2005, online dal 30 novembre 2015, consultato il 21 avril 2021. URL: http://journals.openedition.org/ studifrancesi/35877 ; DOI: https://doi.org/10.4000/studifrancesi.35877

\section{Questo documento è stato generato automaticamente il 21 avril 2021.}

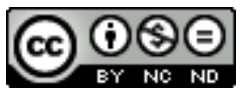

Studi Francesi è distribuita con Licenza Creative Commons Attribuzione - Non commerciale - Non opere derivate 4.0 Internazionale. 


\title{
Maurice Scève, Délie, object de plus haulte vertu
}

\author{
Dario Cecchetti
}

\section{NOTIZIA}

MAURICE SCÈVE, Délie, object de plus haulte vertu, tomes I et II, édition critique par GÉRARD DEFAUX, Genève, Droz («Textes Littéraires Français», 563), 2004, pp. CCL+250 e 490.

Una nuova edizione critica della Délie è apprestata dal grande cinquecentista Gérard Defaux, a una decina d'anni da quella a cura di Françoise Joukovsky (Paris, Dunod, «Classiques Garnier», 1996) e trent'anni dopo l'edizione - la sola veramente completa delle opere di Scève a cura di Pascal Quignard (Paris, Mercure de France, 1974). Ricordiamo pure che recentemente, nel 2001, è stata ristampata, con aggiornamenti di Cécile Alduy, l'edizione di Eugène Parturier (Paris, STFM, 1916). Il testo curato da Defaux riproduce quello dell'edizione pubblicata a Lione nel 1544 (chez Sulpice Sabon, pour Antoine Costantin). Nel secondo volume (di commento) vengono offerte, in testa alla notice consacrata ad ogni dizain, le varianti dell'edizione parigina del 1564. L'introduzione, vera summa di ricerche sceviane che eredita da una tradizione critica illustre dell'ultimo sessantennio (a partire almeno dai debiti, riconosciuti, a Saulnier), costruisce un'ampia monografia (t. I, pp. XI-CCL) sulla Délie e sul suo autore, raccogliendo in primo luogo - arricchendo e aggiornando - un'imponente messe di dati documentari. Nel ricostruire il quadro culturale del canzoniere sceviano e nel ripercorrerne le fonti (da Esiodo a Virgilio, da Dante e da Petrarca a Marot, da Platone a Ficino a Leone l'Ebreo), Defaux non solo porta avanti la sua indagine in profondità, ma apre delle prospettive nuove e interessanti. Come nel capitolo consacrato agli influssi «mariologici» ('Tota pulchra es, amica mea, et macula non est in te': l'amant, Délie et Marie, pp. CII-CLXIII), ove si dimostra come la Délie sia nutrita della poesia mariana del Puy de Rouen. In questa prospettiva Defaux innova anche per quanto concerne il discorso sul senhal (Le choix du 'surnom louable' et celui des cinquante emblèmes, pp. CLXIII-CLXXXVIII). Il soprannome di Délie «è stato scelto da Scève per ragioni che non sono solo legate a 
questioni di onomastica e d'assonanza (Diana, Delos, Délie-l'Idée) o all'innegabile potere evocativo dei miti antichi. [...] A dispetto della loro pertinenza, gli approcci mitologici o cratilici di Coleman, di Duval e di Rigolot non bastano a rendere conto di tutto quello che Scève ha scientemente iscritto nel suo testo. Dopo tutto noi vediamo, sul frontespizio della raccolta Vidoue, che Maria è pulchra ut luna, electa ut sol e che, di conseguenza, la luna è anch'essa - come l'unicorno, come il cedro, come la manna o la mirra - un simbolo mariano» (pp. CLXIII-CLXV). L'intero tomo II è consacrato alle Variantes et notes. Le annotazioni, accuratissime, segnalano tutte le fonti, bibliche e letterarie, e i parallelismi con testi coevi. Inoltre, offrono tutta una serie di richiami interni alla Délie stessa. Il commento puntuale, verso per verso, di ogni dizain è preceduto da un breve sommario interpretativo, vero e proprio discorso esegetico. Non solo il testo dei dizains è commentato, ma anche gli emblemi, ad uno ad uno, sono accuratamente analizzati e inseriti nella tradizione iconografica. Si tratta dunque di un'edizione che diventerà di riferimento. 